\title{
Reconstructing Spatial Image from Natural Language 'Texts
}

\author{
Atsushi Vamada Tadashi Yamamoto Hisashi Ilkeda \\ Toyoaki Vislicla Slunji Doshlita

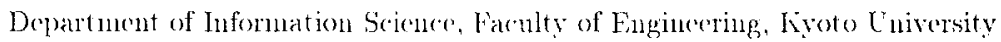 \\ Sakyo-ku. Kroto 606-(0), Japan \\ phone: $+81-75-753-4952$ \\ (tnail: vantadacthuis.kyoto-n.ac.jp)
}

\begin{abstract}
This paper describes the understanding processis of the spatial descriptions in Japunese. In order to understand the described workl. the anthors try to reconstruct the geometric model of the global scene from the scenic descriptions drawing a space. It is done by an experimental computer progran SPlR INT. which takes natural language texts and produces a model of the described world. To reconstruet the nodel. the authors extract the qualitative spatial constraints from the text, and represent them as the munerical constraints on the spatial attributes of the entities. This makes it possible to express the ragueness of the spatial concepts and to derive the maximally plansible interpretation fron a chunk of information acertmulated as the constraints. The interpretation reflects the temporary belief about the world.
\end{abstract}

\section{Introduction}

This paper concentrates on the nuderstanding process of the verbal expressions concening about space. One can casily inagine the described world from the verbal expressions. We regard the intereretation of descriptions as an active process, that is the process of reconstruction of a sitnation which the speaker intended. In this process. one will use many kinds of information. The natural language descriptions contain some of them. and it is very important to extract and use them, but they are not enough. Anong thenn, information about the configuration of the world in one's innage plays an inportiult role.

We have made an experineutial computen program SPRIN'T (for "SP'atial Representation INTerputer"), which takes spatial descriptions written in Japanese. reconstructs 3-dinensional nodel of the workd, and ontputs the corresponding intage on the graphice displiay.

In this paper. We cleseribe the overview of this system.

\section{The Approach}

The esisence of om approach is as follows:

- Meaning of the natural langnage expressions as the constraints anong the spatial entities

- Inage representation of the workd as a collection of the paranceterized entities

- Interpreting the gualitative relations as the numerionl const aints anong the paraneters

- Potential encergy functions for the vapue constraints

- Extracting the procedure of the reconstruction frout the natural language expressions

- Sucessive refinement and modification of the world morlel.

We regard the worle as an assenthly of the spatial entities, and represent each entity as the combination of its prototyge and the real valnes of its prameters. We prepare the graphic objects corresponding to the prototypes. Each graphic object is represented by the parameters prescribing the details of it. The parameters prescribe its location, orientation. and extent.

Now the task becones to generate the graphic: objects comesponding to the described entities and to determine the paraneter values preseribing them. 


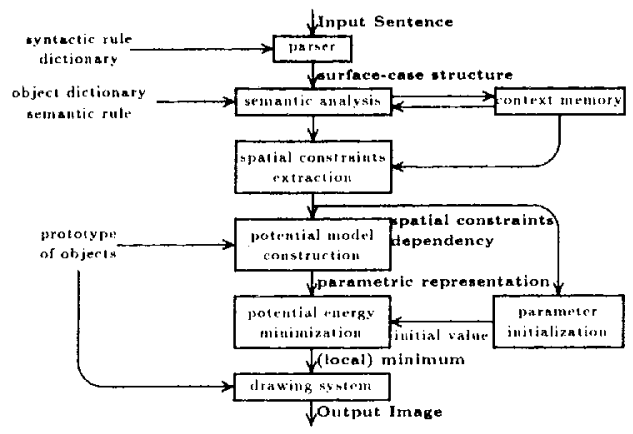

Figure 1: The Overview of the Experinental Syst.en SPRINT

It is difficult to deternine the parancter vahes directly from the natural language descriptions. because of the partiality of the information and the vagueness about the spatial relations anong the entities. So, at first. we extract such information as the cualitative spatial constraints anong the spatial attributes of the entities, and then. interpret these constraints and calculate the parameter values. This process is shown in figure 1.

Given a text, SPRINT makes a surface case structure using the lexical information. Each entity is described as a now1. Next. SPRINT extracts spatial constraints about the entities by analyzing the related words in the case stuncture. At this time. SPRINT also extructs the secuence of the information references from the lexical information as dependencies. which are used as cues in the ralculation of the paraneters.

At the next stage. the extracted qualitative constraints are interpreted as the numerical constraints anong the entity paraneters. These nutmerical constraints are represented as the counbination of the primitive constraints. The potential energy function is one of such prinitives, and this is an efficient method to treat the vagueness in the constraints. Other primitives are the topological constraints and the regions. The potential energy function is a kind of the cost functions which takes all related parameters aurl output. the cost. The less the value of the potential en- ergy function. the more credit the combination of the geometric parancters gains. Using the gradient descendent method, the solution with minimum cost is calculated. The potential energy function provides a means for accumulating from franguentary information. (The basic idea of the potential energy function is reported in [4].)

\section{The Example}

Suppose that the following sentences are the inputs to SPIRINT.

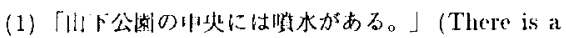
fountain at the center of the Yamashita Park.)

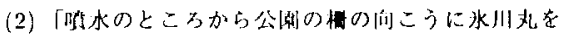
見ることがでる。」 (From that place, you can see Hikawa-mann (a ship) beyond the fence of the park.)

(3)「水川㚘の们的はせリンタワーがたって wる。」 (There is a mariue tower to the right hand of Hikawa-maru.)

From these sentences, SPRINT gets the surface case structures and interprets each connection in the structures to extract spatial constraints. The extracted constraints in this exanple is shown in table 1.

Then SPRINT calculates the entity paraneter values based on these constraints using potential energy functions. The example of the pot.ential cuergy function is shown in figure 2. This is one which is used to calculate the location of the ship. In this figure. the line represents the edge of the park. and the thither side of the line means the inside of the park. Finally SPRINT draw a world image on the graphic display. This is shown in figure 3.

\section{The Analysis of the View}

In the last example. the treatment of the view is very important. Usually an observer sees the world and notices how the world is. If you did not know which direction the observer sees. yon would not determine the direction "to the right" and conled not inagine whene the tower is. Another way to determine the direction "to the 
Table 1: 'The Fxtracted Spatial Constraints

- The Spatial Entities in the Workd

Yaublshita Park (a park), a foumtain, a forces. Hikawa-mat'u (a ship), a matriur tower (a lowers)

- T'he Relations annosig the bintitices

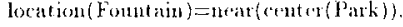
juside(region( (Pak))

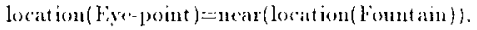
ont side(region(Fonnt ain))

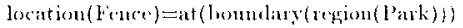

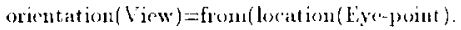
tollocation(Fence)

Jocation (Ain-point) $=$ hintes (Fence. Eyr-pesint $)$. location(Ship)

location (Tower) =right(Ship). Fye-point)

- The Used Knowledgre about the Futitie's

Park = Twodimedsional region (a kind of (inomitul)

Fonntain = Three-dintensionat object with Whtor

Fence $=$ Theredinamsional object at the bonutary of the two-dinembional region

Ship = Three-dine'nsional objece (a kind of rihicke on Water)

Towes $=$ Three-dine ensional object (a kind of Building )

- The General World Kinowledge

Any two objerts caunot occupy the same place. at the same time.

Every object is under the law of gravitution (i.e. it nust suppoterl unless a special reason). Every object has its plausible extent.

There exists a distance scale ancording to the externt.

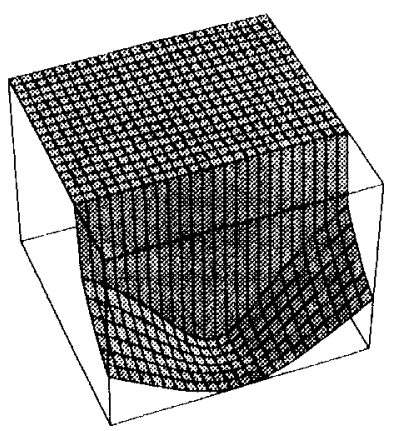

Figure 2: 'l'he Example of the P'otential Energy Fuuction

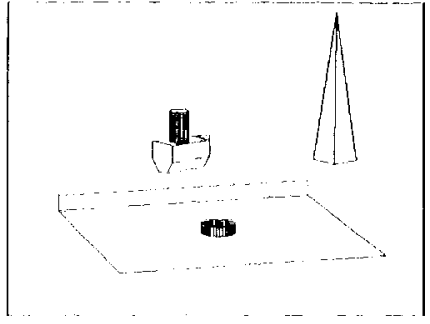

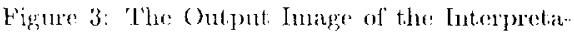
tiont

Tathe 2: 'Jhe Basio Constraints from the Hyo Point:

- fonstrain the erre proint by the point of "obleservation"

const min the anu point by the aimed entity

- constrain the view by the ege point

- contitrailu the view by the aim point

- constrain the view by llee eye diecetion

right," is to calculate it only from the orientation of the ship. but we do not think it is nestal. 'This: means that the spatial inage reflects the history of the inference atud the coustructed innige is used again to nuderstand the wext sentence.

So SPRINT also hat to

- purste of the ese proint of the oldserver.

- set the vinw of the obserser from the eye point.

- infer the spatial configmation from the view.

Fon this sike, we noreled the view of the observer as one of the sputial entities. which hats the eye point. the ain point. and the eye direce tion. In this section, we analyon the descriptions ilbont view in details.

At first. we defime the relalion about "see" its follows:

"There is no visible obstar les between the eye point and the aimed entity."

'The constraints abont the oys point, eye direstion, and the aim point comes from this definition.

The simplest case is shown in table 2. For exanple, there are 5 constraints to the sen-

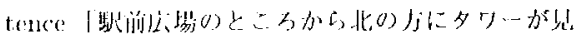


える」(Yon call see a tower north from the station scuare.)
(A) location(Eye-point 1)=Station Squale
(B) location(Aim-point 1)= Tower
(C) start-point (View1)=Eyc-point 1
(D) end-point(View1)=Ain-point 1
(E) $\operatorname{direction}($ Yjew1) $=$ Torth

If the eye point has its own direction. the 5th constraint in 2 becomes in relative one based on the dinetion of the eye point. Fon exanples to

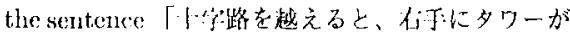
見える」 (If you get across the crossroad. Yon can see a tower to the right hand.) the constraint (E) above becomes

$\left(\mathbf{E}^{\prime}\right)$ direction (riew1)=to-the-right (riew-point2) which means the direction "to the right" is determined by the direction of the cye of the olserver. In this case the observer get across the crossroad and no other information is obtained. so the direction of the eye is determined as the same as that of the transfer of the observer.

There are the cases where the direction of the eye changes anong the transfer. In such cases, the last eye direction must be calculated according to the intermediate clunges. So the change point is put. and it mediates the change of the direction of the transfer. The necessary constraints are as follows:

- constraint about the change point

- constraint about the transfer before the change

- constraint abont the transfer after the cliange

For example, there are 5 constraints for the sentence「十字路を古折する」 (turn left at the crossroad)

(A) location(Change-point 1) $=$ Crossroad

(B) start-point (Transfer-vector 1$)=$ the last Eye-point

(C) end-point (Transfer-rector 1 ) $=$ Changepoint 1

(D) start-point (Transfer-vector 2$)=$ Changepoint 1

(E) direction(Trausfer-sector2) $=$ to-theleft(Transfer-vector 1)

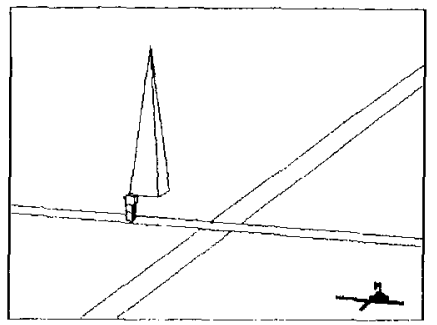

Figure 4: The View Interpretation of the Transfer with the Intermediate Change

The direction of the eye after the change is same as the direction of the transfer-vector2. For ex-

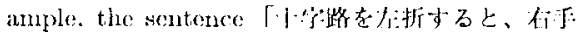
にタワーが見える」(If you turu left at the crossroad, you can see a tower to the right hand.) is interpreted as in figure 4 . In this case, the direction "to the righte" is calculated from the last direction of the eyc.

This interpretation satisties the constraints in the sentence, however, one mity think this is not the same as ho/she imagine becanes in this interpretation the observer can see the tower even before the crossroad. The sentence "If you turn left ..." secms to innly that. "until you turn left. at the crossroad, you cannot see a tower yet." and this is not in the case of the logical sense. Of course this is not always truc. Suppose the situation where you see a tower now and are told the last sentenee (probably in English you say not "a tower" but "the tower"). this will be the case of the integration of the several views. So the ardditional pragmatic constraints are strongly influenced by the purpose of the utterance.

Anyway if you do not want to see a tower before the crossroad. one of the solutions to this problem is like this: put sone obstacle on the view of the observer before the crossioad, that means put it between the point of the observer and the tower. In this case, till the observer turn at the corner, there is no way to know the location of the tower. so no way to put the obstacle. The interpretation acrording to this solution is shown in figure 5.

One of the other solutions is that you know 


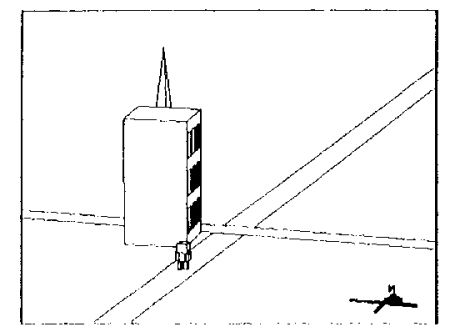

Figme: 5: The View Interpretation with the Adeled Obstacle

there is buildings or something along a street and use them as a obstacle.

This kind of 'invisible' sitnation must be cliscussed with respect to the read world and the daily language use.

\section{Related Work}

From the pure linguistic point of view, A. Henskovits [1] analyzed locative expressions in English. As for constructing a computer model. conventional logic falls short of on purpose. Among the formulations based purely on conventional logice, nost. typical is slot-filler representattion such as a formulation by Gordon Novak Jl [2]. There also is a work by D. Waltz[3]. It is however harch to draw logical conclusion ont of a set of axions which may involve predicates vague and to get a rousable model of the workl configuration.

Our approach allows both contimous and discontimous functions to represent spatial constraints. so that the probability changes either contimuously and discontinuously.

It also works as a chunk of the information. 'Though it seems that our approach is rather subjective, it secms inupossible to constinct a model for the world withont sone kind of subjective.

\section{Conclusions}

We have presenterl an experimental computer program which produces 3-dinensional inage ats an interpretation of the given natital language texts. The area of space-language relationship contains a lot of hard issues. and some problems related to this work are mentioned below.

- presentiation of the innage.

Oui program makes a internal 3-clinensional model of the world, but the presentation on the screen is now mamally done. which moans that the canera position for the computer graphices is manually decided (it is nsmally a birds-eye view). How to present the intermal configuration on an image is a further problem.

- integration of the initial inage.

If all the nodel is constructed based on the verbal information, how to give the initial vahes of the paraneters effectively becomes the problen. If the the reconstruction begins with an initial inage the integration of that image and the verbal information is the other problem. (Probably the initial innge is also vague.)

We are now considering the pratgmatic use of the verbal expression in the world model. and making a model of the visual disappearance.

\section{References}

[1] A. Herskovits. Lamuauge and Spatial Cognition. Cambridge University Press, 1986.

[2] G.S. Novak Jr. Representations of knowledge in a progran for solving physics problems. In Proc. IJCAI-77, pages 286 291, 1977.

[3] ID.L. Walt\%. Trowards a detailed model of processing for language describing the physical world. In Proc. IJCAI-81, pages 1 6. 1981.

[4] A. Yantadiu, 'J'. Nishidia. and S. Doshitid. Figuring out most platusible interpretation from spatial descriptions. In Proc. COLING-88. pages $764 \cdot 769,1988$. 